\title{
A cross sectional study of renal involvement in tuberous sclerosis
}

\author{
J A Cook, K Oliver, R F Mueller, J Sampson
}

\begin{abstract}
Renal disease is a frequent manifestation of tuberous sclerosis (TSC) and yet little is known about its true prevalence or natural history. We reviewed the notes of 139 people with TSC, who had presented without renal symptoms, but who had been investigated by renal ultrasound. Information on the frequency, type, and symptomatology of renal involvement was retrieved.

The prevalence of renal involvement was $61 \%$. Angiomyolipomas were detected in $49 \%$, renal cysts in $32 \%$, and renal carcinoma in $2 \cdot 2 \%$. The prevalence of angiomyolipoma was positively correlated with age, compatible with a two hit aetiology. Renal cysts were the commoner lesion in young children, and their prevalence did not appear to be age related.

Renal investigation in people with TSC had been inconsistent and limited. We suggest guidelines for renal investigation in those with TSC.
\end{abstract}

(f Med Genet 1996;33:480-484)

Key words: tuberous sclerosis; angiomyolipoma; renal cyst.

Tuberous sclerosis (TSC) is an inherited autosomal dominant neurocutaneous syndrome and figures suggested for the incidence of TSC vary from 1 in 6000 to 1 in $15000 .{ }^{1}$ The clinical manifestations result from hamartomas involving multiple organ systems, including the brain, skin, eye, lung, heart, and kidney. The involvement in persons with TSC can vary from very mild (a few skin lesions, a specific neuroradiological finding of TSC on CT scan, but no evidence of fits or mental retardation) to severe with fits which are difficult to control, mental retardation, and severe skin and visceral involvement. $^{2}$

TSC exhibits locus heterogeneity with clinically indistinguishable disease being caused by mutations in two different genes. One gene (TSC2) has been identified on chromosome $16^{3}$ and a second gene (TSC1) has been localised on chromosome $9 .{ }^{4}$

Renal disease is the second commonest cause of death in patients with TSC after central nervous system causes and the commonest cause of death in those over the age of $30 .{ }^{5}$ If better management of neurological complications through improved imaging, antiepileptics, and neurosurgery improves survival, renal involvement might be expected to become a more important medical complication of TSC.
There are two characteristic types of renal involvement in persons with TSC. (1) Angiomyolipomas. These are benign neoplasms composed of mature adipose tissue, thick walled blood vessels, and smooth muscle in varying proportions. In the general population they are a rare finding affecting predominantly women $(80 \%)$ in the third to fifth decade. About $50 \%$ of people with angiomyolipomas have no stigmata of TSC and usually have a large, single angiomyolipoma. ${ }^{6}$ In TSC the angiomyolipomas tend to be small, multiple, and bilateral. ${ }^{7}$ Stillwell et $a l^{7}$ suggested that there was an increase in the prevalence of angiomyolipomas with age but only a limited number of persons with TSC were studied. (2) Renal cysts. These have a characteristic histology in TSC. They are lined with a hyperplastic epithelium consisting of eosinophilic, columnar cells with a "piled up" appearance. This allows them to be differentiated from both autosomal recessive and autosomal dominant polycystic kidney disease. They can arise from all portions of the nephron and are characteristically bilateral, multiple, and of variable size. $^{8}$

A number of reports have also suggested that there may be an increased incidence of renal carcinoma in TSC. $^{79}$

\section{Methods}

A renal database for TSC was created. In order to be added to the renal database, people with TSC had to fulfil the following criteria: (1) they met the definitive diagnostic criteria for $\mathrm{TSC}^{2}$; (2) the date of birth was known; (3) the patient had had a renal ultrasound, the results were accessible, and the date of the scan was known.

In an attempt to eliminate possible bias, patients who presented because of symptoms owing to renal involvement before the diagnosis of TSC was made were not included. Over 450 sets of case notes were reviewed in the two centres (Leeds and Cardiff) which led to 139 persons with TSC being added to the database. The information that was extracted from the notes included the reason for initial referral and symptoms and signs of TSC, including renal symptoms and signs. Results and timing

Table 1 Reasons for referral

\begin{tabular}{lr}
\hline Fit control & 50 \\
Specialist opinion & 41 \\
Genetic counselling/family history & 21 \\
New diagnosis of TSC & 15 \\
General deterioration & 8 \\
Behavioural problems & 4 \\
Total & 139 \\
\hline
\end{tabular}


Table 2 Type and frequency of complications associated with renal disease

\begin{tabular}{|c|c|c|c|}
\hline & Numbers & Type of involvement & \\
\hline $\begin{array}{l}\text { Total number of } \\
\text { patients with renal } \\
\text { lesions }\end{array}$ & $85 / 139$ & $\begin{array}{l}\text { Angiomyolipomas only } \\
\text { Cysts only } \\
\text { Both lesions }\end{array}$ & $\begin{array}{l}40 / 85 \\
17 / 85 \\
28 / 85\end{array}$ \\
\hline $\begin{array}{l}\text { Symptomatic patients } \\
\text { with renal lesions }\end{array}$ & $13 / 85$ & $\begin{array}{l}\text { Angiomyolipomas only } \\
\text { Cysts only } \\
\text { Both lesions }\end{array}$ & $\begin{array}{l}7 / 13 \\
1 / 13 \\
5 / 13\end{array}$ \\
\hline Frank haematuria & $9 / 13$ & $\begin{array}{l}\text { Angiomyolipomas only } \\
\text { Cysts only } \\
\text { Both lesions }\end{array}$ & $\begin{array}{l}4 / 9 \\
1 / 9 \\
4 / 9\end{array}$ \\
\hline Abdominal pain & $4 / 13$ & $\begin{array}{l}\text { Angiomyolipomas only } \\
\text { Cysts only } \\
\text { Both lesions }\end{array}$ & $\begin{array}{l}2 / 4 \\
0 / 4 \\
2 / 4\end{array}$ \\
\hline $\begin{array}{l}\text { Impaired renal } \\
\text { function on U\&E }\end{array}$ & $4 / 13$ & $\begin{array}{l}\text { Angiomyolipomas only } \\
\text { Cysts only } \\
\text { Both lesions }\end{array}$ & $\begin{array}{l}1 / 4 \\
1 / 4 \\
2 / 4\end{array}$ \\
\hline Recurrent UTI/pyelonephritis & $1 / 13$ & $\begin{array}{l}\text { Angiomyolipomas only } \\
\text { Cysts only } \\
\text { Both lesions }\end{array}$ & $\begin{array}{l}1 / 1 \\
0 / 1 \\
0 / 1\end{array}$ \\
\hline
\end{tabular}

Table 3 Type and frequency of renal lesion

\begin{tabular}{llll}
\hline Patients & $\begin{array}{l}\text { Total } \\
139\end{array}$ & $\begin{array}{l}\text { Male } \\
75(41 \%)\end{array}$ & $\begin{array}{l}\text { Female } \\
82(59 \%)\end{array}$ \\
\hline Any lesion & $61 \%(85)$ & $58 \%(33)$ & $63 \%(52)$ \\
Angiomyolipomas & $49 \%(68)$ & $44 \%(25)$ & $52 \%(43)$ \\
Cysts & $32 \%(45)$ & $32 \%(18)$ & $34 \%(27)$ \\
Angiomyolipomas only & $29 \%(40)$ & $26 \%(15)$ & $30 \%(25)$ \\
Cysts only & $12 \%(17)$. & $14 \%(8)$ & $11 \%(9)$ \\
Both lesions & $20 \%(28)$ & $18 \%(10)$ & $22 \%(18)$ \\
No lesion & $39 \%(54)$ & $42 \%(24)$ & $37 \%(30)$ \\
\hline
\end{tabular}

Table 4 Number and distribution of renal lesions

\begin{tabular}{lll}
\hline & Angiomyolipomas (68) & Renal cysts (45) \\
\hline Multiple & $91 \%(62 / 68)$ & $91 \%(41 / 45)$ \\
Single & $9 \%(6 / 68)$ & $9 \%(4 / 45)$ \\
Bilateral & $84 \%(57 / 68)$ & $82 \%(37 / 45)$ \\
Unilateral & $16 \%(11 / 68)$ & $18 \%(8 / 45)$ \\
\hline
\end{tabular}

of all renal ultrasounds and the results of renal CT scans if they had been performed were entered on the database, as well as the results of tests of renal function, which were principally urea, creatinine, and electrolyte estimations but included creatinine clearance and nucleotide scans in a few cases.

\section{Results}

A total of 139 patients ( 57 male and 82 female) were entered on the database. Their ages ranged from 1 month to 66 years (mean age 19, median age 19). The reasons for referral for these patients are listed in table 1 . Of these 139 patients, 116 were probands and 23 were

Table 5 Frequency of renal angiomyolipoma according to age and sex

\begin{tabular}{llcrr}
\hline Age & $\begin{array}{l}\text { Total number } \\
\text { of patients }\end{array}$ & $\begin{array}{l}\text { Total number of patients } \\
\text { with angiomyolipomas }\end{array}$ & Males & Females \\
\hline$<5$ & 26 & $2(8 \%)$ & $0 / 11(0 \%)$ & $2 / 15(13 \%)$ \\
$5-10$ & 14 & $5(36 \%)$ & $1 / 7(14 \%)$ & $4 / 7(57 \%)$ \\
$10-20$ & 32 & $15(47 \%)$ & $4 / 12(33 \%)$ & $11 / 20(55 \%)$ \\
$20-30$ & 32 & $20(62 \%)$ & $11 / 16(69 \%)$ & $9 / 16(56 \%)$ \\
$>30$ & 35 & $26(74 \%)$ & $9 / 11(82 \%)$ & $17 / 24(71 \%)$ \\
\hline
\end{tabular}

Table 6 Frequency of renal cysts according to age and sex

\begin{tabular}{llcll}
\hline Age & $\begin{array}{l}\text { Total number } \\
\text { of patients }\end{array}$ & $\begin{array}{l}\text { Total number of patients } \\
\text { with renal cysts }\end{array}$ & Males & Females \\
\hline$<5$ & 26 & $6(23 \%)$ & $3 / 11(27 \%)$ & $3 / 15(23 \%)$ \\
$5-10$ & 14 & $4(29 \%)$ & $1 / 7(14 \%)$ & $3 / 7(43 \%)$ \\
$10-20$ & 32 & $10(31 \%)$ & $3 / 12(25 \%)$ & $7 / 20(35 \%)$ \\
$20-30$ & 32 & $7(22 \%)$ & $5 / 16(31 \%)$ & $2 / 16(12 \%)$ \\
$>30$ & 35 & $18(51 \%)$ & $6 / 11(54 \%)$ & $12 / 24(50 \%)$ \\
\hline
\end{tabular}

secondarily ascertained affected relatives. It had been hoped to compare data from the two groups, as secondarily ascertained relatives with TSC often have milder involvement than probands. However, the group was too small for meaningful comparison.

Of the 139 patients studied, $85(61 \%)$ had renal lesions, $58 \%$ of the males and $63 \%$ of the females. Of these, 12 had also had renal CT scans which had confirmed the findings on ultrasound. Most patients with renal lesions were asymptomatic. Only 13 out of 85 patients (15\%) had any symptoms (table 2 ). The commonest symptom was frank haematuria which occurred in $9 / 13$ symptomatic patients $(9 \cdot 4 \%$ of all patients with renal lesions). Haematuria was associated with angiomyolipomas in the majority of cases (8/9). The incidence of microscopic haematuria may be much greater than this but, almost invariably, routine urine microscopy was not carried out.

Other symptoms included abdominal pain and recurrent urinary tract infections. $\mathrm{Ab}-$ dominal pain occurred in four patients, all of whom had angiomyolipomas. Blood pressure was only recorded in one set of notes. Of the 139 patients' notes we examined, only 45 had a documented urea, creatinine, and electrolyte result. Only four patients had a serum creatinine level outside the normal range and none had reached end stage renal failure. Creatinine clearance levels had been performed for two of these patients and were impaired in both. There was an equal distribution of angiomyolipomas and cysts among the four patients with impaired renal function, two had both angiomyolipomas and cysts, one had angiomyolipomas only, and one had cysts only.

Two patients had required embolisation of bleeding angiomyolipomas and one had required a nephrectomy because of massive haemorrhage from an angiomyolipoma leading to necrosis of the kidney. A second patient had a nephrectomy because massive kidney enlargement from angiomyolipomas within the kidney and in the perirenal fat was thought to have led to portal vein obstruction. This case is complicated as the patient also has protein $C$ deficiency and it is unclear whether the obstruction was the result of thrombosis or an external pressure effect from the angiomyolipomas.

We analysed the prevalence and type of renal involvement by sex (table 3 ). The proportion of males and females with renal lesions did not differ significantly. Angiomyolipomas were the commonest lesion, occurring in $49 \%$ of all patients. Of those with angiomyolipomas, $91 \%$ had multiple lesions and $84 \%$ had bilateral lesions (table 4). Cysts occurred in $32 \%$ of all patients, with $91 \%$ having multiple cysts and $82 \%$ having bilateral cysts (table 4 ). Angiomyolipomas and cysts occurred together in $20 \%$ of all patients.

The data were also analysed by age at time of radiological examination (tables 5 and 6, figs 1 and 2). The incidence of renal angiomyolipomas increased with age. The product moment correlation coefficient ${ }^{10}$ was 0.91 $(p<0.05)$ indicating significant positive cor- 


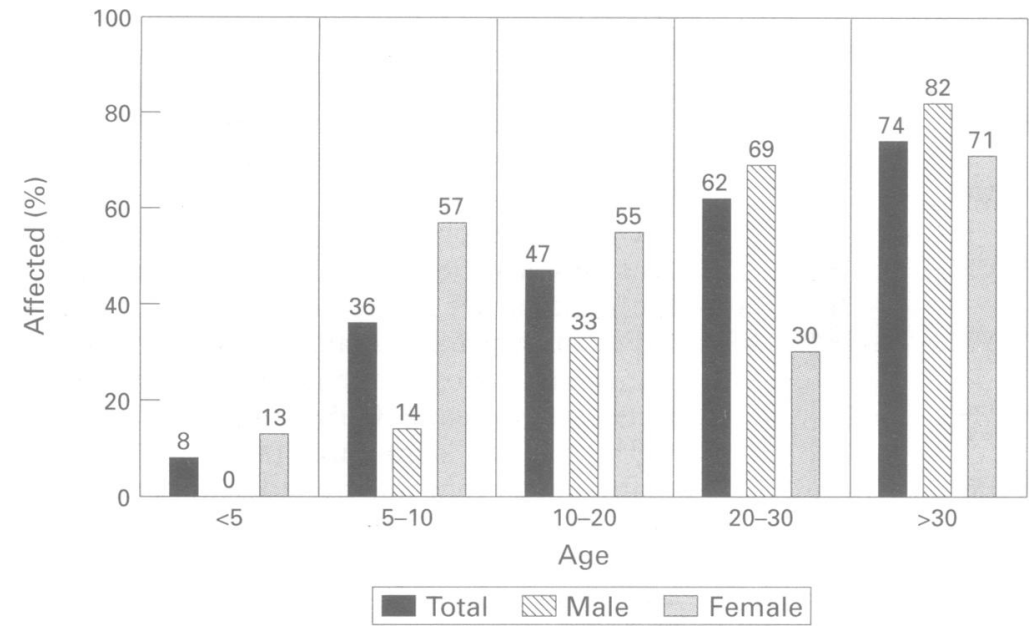

Figure 1 Frequency of angiomyolipomas according to age and sex.

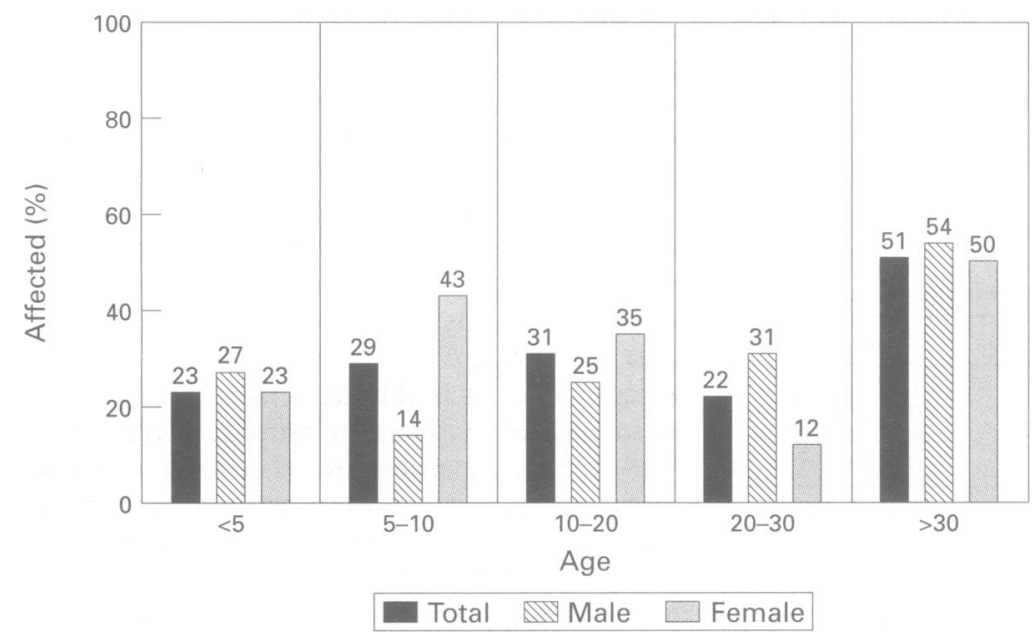

Figure 2 Frequency of renal cysts according to age and sex.

relation between age and increasing prevalence of angiomyolipoma. The incidence of renal cysts did not show a significant positive correlation with age (correlation coefficient 0.79 , $0 \cdot 1<\mathrm{p}<0.2$ ).

Three cases of renal carcinoma were identified among the 139 patients (table 7). Only one of these patients died from his tumour and this was the only death in the group from renal complications.

The prevalence of other features of TSC was investigated to see if any were associated with renal disease. The prevalence of facial angiofibromas in patients with renal involvement was $64 \%$ compared to the reported incidence in TSC of 70 to $83 \% .^{2}$ The prevalence of mental retardation in patients with renal involvement was $49 \%$ compared to the reported incidence in TSC of $38 \% .^{11}$ These figures would suggest that renal involvement occurs independently of other manifestations of TSC.

Table 7 Cases of renal carcinoma

\begin{tabular}{llll}
\hline & Age & Sex & Type of involvement \\
\hline Case 1 & 21 & $\mathrm{~F}$ & Angiomyolipomas and cysts \\
Case 2 & 39 & $\mathrm{~F}$ & Angiomyolipomas and cysts \\
Case 3 & 66 & $\mathrm{M}$ & Angiomyolipomas and cysts \\
\hline
\end{tabular}

\section{Discussion}

Our study confirmed that renal involvement in tuberous sclerosis is common; $61 \%$ of patients had renal lesions detectable by renal ultrasound scan. However, since we did not have a large number of secondarily ascertained patients, this figure may still not be an accurate representation of the true incidence of renal disease in TSC. Most patients with renal involvement were asymptomatic. In general, renal symptoms were only recorded in the notes if volunteered by the patient rather than being specifically elicited. The incidence of renal symptoms may be higher, particularly in the mentally handicapped who may not be aware of symptoms referrable to the renal tract. However, of 68 patients with angiomyolipomas, eight $(12 \%)$ had frank haematuria and two required embolisation to control the haemorrhage. This was performed percutaneously via the femoral artery. Two further patients had nephrectomies.

Only a third of the patients in this study had had any investigation of renal function. In most of these cases, urea, creatinine, and electrolytes had been measured. A large proportion of renal function is lost before these indices become abnormal, but more sensitive tests of renal function such as creatinine clearance had not been performed in the majority of patients. Hypertension might also be anticipated in a group of patients with extensive renal disease, but virtually none of the patients had had routine blood pressure measurements. This may reflect a lack of awareness of renal complications in TSC.

Angiomyolipomas were the commonest type of renal lesion, occurring in $49 \%$ of patients. They were usually both multiple and bilateral. A study by Stillwell et al suggested that the prevalence of angiomyolipomas increases with age. Our study has confirmed this finding. Although our data are limited, they indicate that females with TSC develop angiomyolipomas at a younger age than the males. This was also suggested by the smaller study of Webb et $a l .{ }^{12}$ The results from our study, however, are not statistically significant $(0.5<p<0.1)$ and greater numbers are needed to confirm or refute this suggestion. It may be relevant that angiomyolipomas in non-TSC patients (which are generally solitary) are also much commoner in females than males. ${ }^{6}$ Although hormonal factors are a possible explanation for this observation, it is not clear why females with TSC have a greater likelihood of developing angiomyolipomas compared to males, under the age of 10 .

Green et $a l^{13}$ have suggested that a two hit mechanism involving somatic loss of the normal TSC allele leads to formation of angiomyolipomas and other hamartomatous lesions seen in TSC. While an age related increase in prevalence of angiomyolipomas is consistent with this model, the sex difference observed in angiomyolipomas indicates that other factors are also involved.

As most angiomyolipomas in TSC are bilateral and multiple, management needs to be as conservative as possible. Current re- 
commendations take account of their size and the presence or absence of symptoms. ${ }^{14}$ Van Baal et $a l^{15}$ reported a relationship between the size of angiomyolipomas and their risk of bleeding. They suggested that small, asymptomatic tumours should be monitored regularly and recommended an aggressive approach of prophylactic selective embolisation for tumours greater than $3.5 \mathrm{~cm}$ before they bleed. If surgery has to be performed to control bleeding this should be a partial nephrectomy if possible.

The prevalence of renal cysts in our study was $32 \%$ and the prevalence did not show a correlation with age, suggesting a different developmental basis to that of angiomyolipomas. The incidence of renal cysts did rise in the over 30 age group, but so does the incidence of renal cysts in the general population $^{16}$ and this may be complicating the picture. Two of the patients in this age group had single cysts.

In children under the age of 5 years cysts were a more common lesion than angiomyolipomas. Renal cysts in TSC have been reported antenatally ${ }^{17}$ and in a neonate at birth, when they were seen to enlarge over a period of months. ${ }^{18}$ Because other features of TSC are frequently absent in infancy some cases have initially and erroneously been diagnosed as having autosomal recessive polycystic kidney disease or infantile presentation of autosomal dominant polycystic kidney disease. ${ }^{19}$ More recently, some infants with severe polycystic kidneys have been shown to have a contiguous deletion of the TSC2 gene and the adjacent autosomal dominant polycystic kidney disease gene, PKD $1 .{ }^{20}$

Yu $e t a l^{1}$ and Okada $e t a l^{2}$ have suggested that the major predisposing factor in the development of renal failure in people with TSC is the presence of cystic disease. In our series only four patients had recognised renal impairment. Of these two both had angiomyolipomas and cysts, one had angiomyolipomas only, and one had cysts only.

Three patients in the study developed renal cell carcinoma, all three having coexisting angiomyolipomas and cysts. The incidence of renal cell carcinoma in the general population is $7 \cdot 5 / 100000$. When Washecka et al reviewed published reports on malignant tumours in TSC, they noted that half the tumours reported were bilateral compared to the population incidence of bilateral tumours which is 1.6 to $3 \cdot 8 \%$. The median age for development of renal carcinoma in the general population is about 60 . In our study the patients were aged 27,35 , and 65 years. Although our numbers are small they would appear to add to the body of evidence suggesting that there is an increased incidence of renal cell carcinoma in TSC.

None of the patients in our study had reached end stage renal failure, but both dialysis and renal transplantation have been undertaken successfully in patients with TSC. ${ }^{23}$ Most TSC patients receiving renal replacement therapy have had only minor CNS dysfunction, possibly reflecting the unwillingness of doctors to take on dialysis and transplantation in the mentally handicapped patient. In view of the apparent increased risk of renal carcinoma in TSC it has been suggested that bilateral nephrectomy should be performed before transplantation. If this is not done the native kidneys should be routinely evaluated with ultrasound.

This study has shown that a majority of patients with TSC develop renal involvement and that in a minority of cases this results in significant morbidity. However, we have found that comprehensive renal assessment is rarely undertaken. The study highlights the need for a large longitudinal study on which recommendations for renal surveillance can be based. We are now collecting data prospectively and are using the following guidelines. We undertake a baseline ultrasound of the kidneys in all patients. In those without evidence of renal involvement, we suggest that renal ultrasound should be repeated at least every five years. Van Baal et $a l^{15}$ have suggested that, in cases with renal disease, follow up scans be performed at six monthly intervals. However, in their study only $20 \%$ of patients with angiomyolipomas showed an increase in size of the lesions after five years of follow up. We are adopting a more conservative regimen and perform follow up scans every one to two years. If there is any doubt about the nature of a lesion a CT or MRI scan can help to differentiate between angiomyolipoma and carcinoma.

Regular blood pressure measurements and tests of renal function should be performed if there is extensive renal involvement. If possible, episodes of bleeding should be treated conservatively by embolisation of individual lesions and, if this is not possible, by partial nephrectomy rather than total nephrectomy. Prophylactic embolisation of large angiomyolipomas may be considered but more data on the risk of haemorrhage are required before guidelines can be drawn up. Dialysis and transplantation should be considered for patients in end stage renal failure.

Further work needs to be done to assess whether specific subgroups of TSC patients are at risk of developing renal insufficiency. Serial renal ultrasounds will provide further information on the natural history of renal disease in TSC and this may allow future modification of the suggested surveillance protocols. Longitudinal studies may also provide insights into the aetiology of renal carcinoma in persons with TSC.

Financial support for this project was provided by the Tuberous Sclerosis Association of Great Britain.

1 Webb DW, Osbourne JP New research in tuberous sclerosis. $B M 7$ 1992;30:1647-8.

2 Gomez MR. Tuberous sclemosis. 2nd ed. New York: Raven Press, 1990.

3 The European Chromosome 16 Tuberous Sclerosis Consortium. Identification and characterization of the tuberous sclerosis gene on chromosome 16. Cell 1993;75 1305-15.

4 Nellist M, Brook-Carter PT, Connor JM, et al. Identification of markers flanking the tuberous sclerosis locus on chromosome 9 (TSC1). $\mathcal{F}$ Med Genet 1993;30:224-7.

5 Shepherd CW, Gomez MR, Crowson CS. Causes of death in patients with tuberous sclerosis. Mayo Clin Proc 1991; 66:792-6.

6 McCullough DL, Scott R, Seybould HM. Renal angiomyolipoma (hamartoma): review of the literature and report of 7 cases. 7 Urol 1971;105:32-44.

7 Stillwell T, Gomez M, Kelalis P. Renal lesions in tuberous sclerosis. f Urol 1987;138:477-81.

8 Stapleton B, Johnson D, Kaplan G, Griswold W. The cystic renal lesion in tuberous sclerosis. $\mathcal{F}$ Pediatr 1980;97:574-9. 
9 Washecka R, Hanna M. Malignant tumours in tuberous sclerosis. Urology 1991;37:340-3.

10 Altman, D. Practical statistics for medical research. London: Chapman and Hall, 1991.

11 Webb DW, Fryer AE, Osbourne JP. On the incidence of fits tion in tuberous sclerosis. $7 \mathrm{Med}$ 1991;28:395-7.

12 Webb DW, Kabala J, Osbourne JP. A population study of renal disease in patients with tuberous sclerosis. $\mathrm{Br} \mathcal{F} \mathrm{Urol}$ renal disease in

13 Green A, Smith M, Yates J. Loss of heterozygosity on chromosome $16 \mathrm{p} 13.3$ in hamartomas from tuberous sclerosis patients. Nature Genet 1994;6:193-6.

14 Oesterling JE, Fishman E, Goldman S, Marshall F. The management of renal angiomyolipoma. $\mathcal{F}$ Urol 1986;135: $1121-4$

15 Van Baal JG, Smits NJ, Keeman D, et al. The evolution of renal angiomyolipomas in patients with tuberous sclerosis. f Urol 1994;152:35-8.

16 Ravine D, Gibson RN, Donlan J, Sheffield LJ. An ultrasound renal cyst prevalance survey: specificity data for inherited renal cystic diseases. Am $\mathcal{Y}$ Kidney Dis 1993;22:803-7.
17 Blethyn J, Jones A, Sullivan B. Prenatal diagnosis of unilateral renal disease in tuberous sclerosis. Brf Radiol 1990; 64:161-4.

18 Moss J, Hendry G. The natural history of renal cysts in an infant with tuberous sclerosis; evaluation with ultrasound. Br F Radiol 1988;61:1074-6.

19 Webb D, Super M, Normand C, Osborne J. Tuberous sclerosis and polycystic kidney disease. BMF 1993;306: sclerosis and polycystic kidney disease. BMf 1993;306:

20 Brook-Carter PT, Peral B, Ward C, et al. Deletion of the TSC2 and PKD1 genes associated with severe infantile polycystic kidney disease - a contiguous gene syndrome. Nature Genet 1994;8:328-32.

21 Yu DT, Sheth KJ. Cystic renal involvement in tuberous sclerosis. Clin Pediatr 1985;24:36-9.

22 Okada R, Platt M, Fleishman J. Chronic renal failure in patients with tuberous sclerosis. Association with renal cysts. Nephron 1982;30:85-8.

23 Balligrand J, Pirson Y, Squifflet J, Cosyns J, Alexandre G, Ypersele de Strihou C. Outcome of patients with tuberous sclerosis after renal transplantation. Transplantation 1990; 49:515-8. 